\title{
Introduction
}

\section{On theorising and humanising academic complicity in the neoliberal university}

\section{ALEX POSECZNICK}

KEYWORDS

academia, collusion, complicity, higher education, neoliberalism, power, resistance

Most academics that I know take it for granted that higher education in capitalist countries has become deeply corporatised over the last thirty years. ${ }^{1}$ But as an undergraduate student in the 1990s, dreaming of joining the ranks of the professoriate, the institutional and structural changes that were transforming the university were largely hidden from my view. Looking back, I had no idea how such trends might be impacting the men and women who excited my intellect and set me on an academic path. I did not even think to ask.

In the United States, the academic world is now firmly nested within the higher education industry, but I imagine that few scholars enter the academy actively thinking about this fact. It can seem to those on the outside looking in that the university primarily acts as the repository and producer of Western liberal-philosophical knowledge; a lush, middle-class/affluent space with manicured lawns where serious intellectuals consider the nature of the universe. But those lawns do not manicure themselves. Each institution of higher education must generate enough revenue not only to pay for the gardener, but also for the salaries, facilities and all of the other costs of a large, often residential, commercial enterprise. Differences between the intellectual and commercial endeavours of higher education produce tensions tensions that few academics consider before accepting their first jobs but with which they all must eventually grapple.

As someone who completed doctoral study and experienced the job search during the Great Recession, I am sensitive to a number of these 
tensions. In the extremely competitive academic market, I felt that I needed to package myself as a certain kind of product and, after so many interviews, my 'pure' research interests felt reduced to an advertising jingle. In this process, it was necessary to market my academic expertise and highlight my intellectual capital (including credentials, publications, procurement of research grants, etc.). Similarly, universities produce various marketing materials to promote their most valuable products: faculty. These materials, in print or online, highlight faculty academic expertise and intellectual capital as well. Presumably, this is because potential students and donors are impressed by such markers of prestige; however, not only are such materials actively exploited by the university (in student recruitment or fund-raising), they are also deployed by the faculty themselves (in leveraging remuneration or negotiating positions in other universities as free agents). In the United States, even the professoriate itself has changed: In 1975, nearly half of professors were either tenured or on the tenure track. By 2009, the latest year for which national figures are available, that proportion had dropped to less than a quarter. Over the same time period, the proportion of faculty working part-time increased from 24 per cent to more than 40 per cent, and the percentage of those working full time but off the tenure track rose from about 10 per cent to 15 per cent (Wilson 2013).

The changes in the make-up of the professoriate towards more nontenured, contingent faculty also has implications for academic freedom (the ability to pursue controversial or potentially unpopular research with relative impunity), governance (faculty voice in how a university is run), and undergraduate instruction (which is increasingly handled by graduate students or contingent faculty). In the face of increasing costs, students are forced to rely more on loans in order to earn degrees that are required for jobs that once required only a High School diploma. Some administrators seek cost-saving features in Massive Open Online Courses (MOOCs), which can have enrolments of over 100,000 students. Seemingly, costs increase, salaries freeze and budgets decline. Some see corporatisation as the solution to these problems, and some see it as the cause of them. Although more carefully articulated below, I refer here to the bundles of institutional practices and cultural changes as the neoliberalisation of higher education. These changes do not happen in some distant vacuum, but on our doorstep.

The contributors to this issue all work in academia, and so it is important to emphasise that there is a degree of auto-ethnography in all of these 
works. For myself, I spent about ten years as a part-time adjunct instructor; ${ }^{2}$ I have also worked in university administrations and have completed an ethnography of college admissions (see Posecznick 2013). Most recently, I have taken a hybrid administrative-faculty position at the University of Pennsylvania's Graduate School of Education. My personal narrative is relevant here because it frames the way I have encountered and responded to the neoliberalisation of higher education. Many academics seem to attribute neoliberalisation entirely to the growth of the executive and administrative class in universities, and conflicts in faculty-administration relations certainly seem a locus for related debates. However, in my case, the tenuousness or endurance of my hybrid position lies in my ability to enact both, to be both a member of the faculty and an administrator. In this role, I sometimes offer resistance to neoliberal changes, but often I am complicit. Do I collude? Do we all?

These were the questions I put forward to the authors in preparation for our first encounter at the 110th Annual Meeting of the American Anthropological Association in 2011. The answers we have each struggled with since then and refined as we transformed our initial papers into articles for this special issue. Academics and administrators alike discuss these tensions, but largely in offices, on blogs, in coffee shops, or in the opinion pages of the Chronicle of Higher Education. In other words, we talk about these issues, but relatively few of us have fully brought to bear our intellectual traditions to understand these tensions better. That is the aim of this special issue: ${ }^{3}$ to examine critically the ways that scholars are complicit with and/or creatively resist neoliberal practices in the university. All of the authors are situated in Western settings and, as such, likely share certain core assumptions about neoliberalism, as elaborated below. Some of the authors describe and analyse the institutional rituals, policies and practices that reproduce inequity in their own departments and institutions, while others draw on data from larger studies. Our focus on the social world we inhabit opens up possibilities not only for denouncing some of these neoliberal changes but also for thinking about how we can understand and resist them.

All of the core terms we draw on in this dialogue - collusion, complicity and resistance - are deeply value-laden. Not only do these terms describe a range of responses to hegemony, but they are also suggestive of an ethical orientation to that hegemony; the terms collusion and complicity in particular carry with them a strong negative connotation. Collusion alludes to faculty members not only complying with neoliberal transformations but 
actively embracing such changes; complicity suggests a more nuanced, uneven and potentially subconscious support of certain facets of these changes; and resistance suggests an active opposition to them. Certainly, all of the authors in this issue are united in opposition to such changes, and these word choices reflect our transparency about that opposition; I doubt that any of the authors here would advocate for either collusion or complicity. Of course, faculty opposition or resistance cannot be enacted in every part of one's life, particularly for those occupying liminal, contingent spaces. Still, the possibility for meaningful resistance remains.

What do we mean, precisely, by resistance? The trend in anthropology to examine its colonial roots coincided with a more careful theorising of power and resistance; it is in this context that the works of James Scott $(1979,1985,1990)$ become particularly relevant. Scott articulated the notion of 'hidden transcripts' to point to the ways that the oppressed and the marginalised (often peasants), largely in former colonies, retained both their awareness of their oppression and actively resisted those in power through everyday activities. Some scholars have argued that such resistance was both situated and trivial, but this was a function of the vast disparity in power between the dominated and the dominators and, in some circles, was primarily associated with 'transitions to capitalism in agrarian social relations' (Sivaramakrishnan 2005: 346). Scott’s work, however, acknowledges that 'everyday resistance emphasises a constant strategic alertness on the part of those involved that places a lot of weight on agency and calculation' (Greenhouse 2005). This model of resistance is applicable only so far when discussing the relations between faculty and agents of neoliberalisation. Such neoliberal agents can leverage more resources than many scholars, but it would greatly minimise the condition of peasantry in the post-colony to suggest that Western scholars are somehow as oppressed as peasants. So what model is there for examining power struggles and conflicts among factions that cannot so easily be bifurcated into oppressor and oppressed? Indeed, in some contexts it would be appropriate to formulate this conversation as one in which the structure of power relations is being co-constructed by factions internal to the university; neoliberal agents understand their acts as contesting the deeply entrenched authority of faculty to structure power relations in higher education. But for the increasing number of scholars without tenure (or even the path to it), what forms of meaningful resistance are available aside from acts of micro-resistance - the hidden transcripts of 
Scott? In this issue, the articles by Madeloni and by Ford and Hose highlight these questions, and although we do not yet have clear solutions, all of the articles here suggest some answers.

And collusion? As Cris Shore and Miri Davidson point out in their article in this issue, the notion of collusion connotes both intentionality and a degree of morality or criminality that may not be relevant when describing individual responses to greater systemic structures of which they may or may not be consciously aware. Collusion, in this case, would point to a few individuals willing to use deceitful or questionable tactics in support of a neoliberal agenda. Likewise, one must consider whether collusion is an appropriate term for describing the contest over structuring power relations between two relatively unequal factions. This is largely the case in the academy because agents of neoliberal change are both perceived as being more unified and organised, and often able to leverage financial and institutional capital and resources to achieving their aims above and beyond individual scholars, who may be less likely to organise around effectively collective aims. Regardless, collusion should be used sparingly, as it suggests that the scholar is, by definition, betraying the scholarly community. The far more nuanced response of complicity is perhaps most appropriate.

But what, precisely are we complicit with? What do we oppose? The corporatisation of the higher education industry itself? Our efforts on this front may seem too little and too late. Do we oppose the administration? For many faculty members, the administration is a convenient symbol for all the neoliberal challenges faced in the higher education industry. Certainly, university administration has been radically transformed over the course of the twentieth century. However, as someone who does attempt to walk a line between faculty and administration and who has known many wellintentioned and deeply moral administrators, it seems unfair to impugn an entire class of person for the ills of the era. Clearly, more nuance is required.

Do we oppose the state? Across the world, the state has had an active and historic role in promoting particular projects and agendas, but we must continue to acknowledge that the state 'is not an entity. It is a dynamic field of tension among and within the agencies of government in relation to their wider spheres of interest and operation' (Greenhouse 2005: 360). As with the administration, it is misleading to presume or impose a single agenda onto such a diverse set of actors.

In the end, the authors seem to be most opposed to both the agents and hegemonic forces promulgating neoliberalism and the sense of apathy, 
resignation, or hopelessness that they can engender among academics. To achieve individual academic success, individual scholars must focus on their own research and publication, but to sustain the critical traditions of the academy, they must also address questions of academic freedom, university governance and critical pedagogy. If not, academics implicitly undermine their own institution. The articles by LeCompte and by Madeloni in this issue demonstrate how individual scholars with varying degrees of support can fare against a well-organised, neoliberal machine.

Of course, this discussion of neoliberalism in and of itself may not clarify matters, as neoliberalism has been used by scholars in a variety of ways and contexts. Given a diverse array of neoliberal practices in various local contexts as embedded in economic, cultural and social global-flows, Hilgers (2011) defines neoliberalism broadly as:

A radicalized form of capitalism, based on deregulation and the restriction of state intervention, and characterized by an opposition to collectivism, a new role for the state, an extreme emphasis on individual responsibility, flexibility, a belief that growth leads to development, and a promotion of freedom as a means to self-realization that disregards any questioning of the economic and social conditions that make such freedom possible (Hilgers 2011: 352).

Hilgers also highlights three different approaches generally taken by scholars in the analysis of neoliberalism. The first approach, exemplified by the works of Comaroff and Comaroff (2001), examines neoliberalism as a culture and all that is implicated in culture, including worldview, lifestyle, practice, symbols, relations and institutions. Meanwhile, in a second approach Wacquant $(2008,2009,2010)$ and Harvey (2005) emphasise a systemic approach to understanding neoliberalism, an approach that highlights the networks of relations and structures that operate to accumulate wealth, status and power for global elites as legitimated by an ideology of meritocracy. Inspired by Foucault, a third approach understands neoliberalism as governmentality, a practice that draws upon technologies of subjection and government to infiltrate the political domain with market forces (see, for example, Ong 2006). These approaches are not mutually exclusive but are rather three broad categories that have emerged from anthropological inquiry into this area.

The dialogue about neoliberalism and the university is a discursive battle over what higher education is or should be. But the authors here are not 
opposed to a disembodied set of propositions or ideas; instead, we are opposed to a set of active individuals in various positions of authority who are able to promulgate such ideas and mobilise resources to produce structural changes while imposing sanctions on those who oppose them. These proponents of neoliberalism, however do not occupy a single space in the world around us, and it is dangerous (as with most such assumptions) to see only allies or opponents rather than nuanced individuals with competing agendas and understandings. Some are administrators. Some are executives. Some are faculty members. Others are politicians, public figures and industry leaders. Some are paying customers (i.e. students and their families). They are all complex human beings who defy simplistic stereotypes.

Thus there is a continuum of individual responses to institutional tensions, and not all of them necessarily conform to a deep internalisation that we can reduce to collusion, complicity, or resistance. The articles here describe a very human set of responses to shifting power relations that academics are encountering in the neoliberalising university; most of these articles are about such tensions in the U.S., although other Western countries are implicated as well. Again, many of these accounts are auto-ethnographic, bringing together personal experience and thoughtful reflection on the theoretical aims laid out in this introduction. Many of these accounts highlight, in different ways, the uncertain but growing role of contingent faculty labour in this new dynamic.

Cris Shore and Miri Davidson bring us 'Beyond collusion and resistance: academic-management relations within the neoliberal university', in which they provide a powerful analysis of how neoliberal, market-led, higher-education reforms in New Zealand have reframed the institutions there as quasicommercial enterprises. The authors challenge our notions of collusion and complicity with their nuanced account of the political and legal networks in which the neoliberal university operates.

In 'Science ideals and science careers in a university biology department', David Long analyses science faculty members and American students not engaging the more challenging questions about evolutionary theory versus creationism in university science courses in a part of the United States where evangelical Christians are a significant part of the population. The aversion to meaningful dialogue about the topic partly emerges from a neoliberal understanding of the student as a customer (who is always right) and scientific knowledge as a marketable product; in this setting, faculty members adjust their instructional practices around the expectations of creationist students 
who, in turn, aim to pass through sciences courses as quickly as possible. This dance of mutual complicity (creationist students not challenging evolution and science faculty not challenging creationism) is made meaningful within the context of a neoliberal university - particularly for the contingent faculty labour whose continued employment may require positive teaching evaluations. This article likewise suggests that science faculty are undermining both their own science learning goals and the promise of science as a medium from promoting democracy.

'Caught in the adjunct trap', by Linda Hose and E. J. Ford, draws on auto-ethnographic accounts of the authors' contingent labour in order to challenge more privileged faculty to rethink their own complicity in the neoliberal university. In a marketplace where so few are privileged with a tenure-track seat, taking contingent positions may indicate to some that a scholar lacks the intellect required to succeed. In this piece, however, the trials and travails of casualised labour are brought to life through the individual stories of struggle with inequitable structural positions in the academic hierarchy, one which is statistically likely for many new scholars. ${ }^{4}$

Margaret LeCompte's 'Collusions of culture: academic culture in the neoliberal university' interrogates the long-term, legal battles over faculty governance and academic freedom at an American university vis-à-vis the stories of two faculty members who each challenged neoliberal establishments: one industrial and one political. The author documents and dissects the organised and systematic efforts to discredit these faculty members, as well as the mostly failed attempts at collaboration among the various factions to support them. The implications for academic freedom in particular are troubling and far-reaching.

Barbara Madeloni describes what happens when teacher education in an American university collides with the neoliberal audit culture of American educational reform movements as spearheaded by the National Council for Accreditation of Teacher Education (NCATE). In 'From a whisper to a scream: ethics and resistance in the age of neoliberalism', she describes how faculty members broadly, but contingent faculty in particular, get caught in an ideological vice, one where silence engenders complicity and resistance provokes retribution. Having experienced these processes first hand, Madeloni interrogates her own gendered position as she moved from complicity towards resistance, and the consequences of this movement.

Finally, in 'Wither the welfare state: the new global adventures of higher education', Wesley Shumar provides a broad and historical overview of how 
academics have become implicated in these cultures, systems and neoliberal governmentalities in recent years. He positions the articles of this special issue in the context of systemic, historical and contemporary trends, which allows for the examination of the tensions, contradictions, shifts and fissures that result from treating higher education as an industry and enterprise.

Given the scope of corporatisation in higher education, the array of resources dedicated to its furtherance and so many competing agendas and individuals involved, how can we initiate meaningful change? Multiple layers of change would have to be initiated simultaneously: at a policy level, in research, in classrooms, and in individual lives. For these reasons, Ferguson (2010: 171) is quick to caution against using neoliberalism too loosely, as it can become 'a kind of abstract causal force that comes in from the outside'; such a move grants the phenomena an inevitability that can produce hopelessness:

such an all-encompassing entity can easily come to appear as a kind of gigantic, all-powerful first cause .... This yields empty analysis ... since all one can do with such a gigantic, malevolent 'thing' as 'neoliberalism' conceived in this way is to denounce it (Ferguson 2010: 171).

This is thus the greatest danger: the presumption that the scope of the problems is so vast that it is not worthwhile to change the everyday behaviours or practices that most contribute to those problems; to become jaded, cynical, disheartened or even apathetic. I understand this pressure. I am not on a tenure track, and my own position is contingent upon my ability to embody competing roles. The first step, however, is to acknowledge the shift in power relations that is taking place in the academy and to recognise that, as scholars, we are not as powerless as some might lead us to believe. The authors in this issue do a fine job of just that.

\footnotetext{
Alex Posecznick, PhD, is appointed as a core faculty member at the University of Pennsylvania's Graduate School of Education and manages the graduate programmes in the Division of Education, Culture and Society. His research and professional expertise in the anthropology of post-secondary education provides him with a unique perspective on academic programming, higher education administration and organisational culture. He is a member of the American Educational
} 
Research Association, the American Anthropological Association and the Council on Anthropology and Education, where he served as the co-chair for the committee on Post-Secondary Education from 2010 to 2013 and has recently been named a 2013 Presidential Fellow.

Contact: Graduate School of Education, University of Pennsylvania, 3700 Walnut Street, Philadelphia, PA 19104-6216, U.S.A.

Email: alpos@gse.upenn.edu

\section{Notes}

1. Some have argued that in the United States many universities have seemingly shifted in mission from one where the emphasis was primarily educational to one which is primarily concerned with making a profit (Washburn 2006; Schrecker 2010; Tuchman 2011). This shift has been signalled in part by the expanded use of 'corporate' or 'business' models and jargon for managing the university, including understanding students as 'customers', prospective students as 'market share', faculty as 'labour' and quality as 'brand'. The corporatisation of higher education involves active re-structuring while neoliberalism points to the cultural logic, system or means of disciplining that are seen as undergirding these changes (see below); the two thus go hand-in-hand. Shumar's conclusion (this issue) highlights these trends in Western higher education.

2. In the United States the term 'adjunct' is frequently used to describe part-time, contingent faculty members who teach on a course-by-course basis; careers can thus be stitched together by teaching across several universities at the same time. Many of the articles in this issue mention the trend towards heavier and heavier reliance on such labour pools.

3. As all of the scholars here broadly associate themselves and their work with cultural anthropology, this particular academic discipline shapes the arguments and assumptions of all the articles presented here.

4. A number of editorials in the Chronicle of Higher Education have confronted academics with the rising tension that comes from having faculty mentors who expect their doctoral students to obtain tenure-track jobs immediately after completion of study and the growing number of new scholars who cannot do so, as well as what has come to be known as the 'altac' career track ('alternative academic', i.e. scholars seeking jobs outside of academia entirely). These include Racket's (2011) piece struggling with survivor's guilt out of being one of the few to obtain a job, Adams' (2012) advice on how to handle optimistic advisees who want to pursue doctoral study and Shullenberger's (2013) struggles to obtain affordable healthcare in the face of his being part of the marginal, 'adjunct majority'.

\section{References}

Adams, H. (2012) 'Enlightening advisees', Chronicle of Higher Education, 1 March. 
Comaroff, J. and Comaroff, J. (eds) (2001) Millenial Capitalism and the Culture of Neoliberalism, Durham and London: Duke University Press.

Ferguson, J. (2010) 'The uses of neoliberalism', Antipode 41, no. 1: 166-184.

Greenhouse, C.J. (2005) 'Hegemony and hidden transcripts: the discursive arts of neoliberal legitimation', American Anthropologist 107, no. 3: 356-368.

Harvey, D. (2005) A Brief History of Neoliberalism, Oxford: Oxford University Press.

Hilgers, M. (2011) 'The three anthropological approaches to neoliberalism', International Social Science Journal 61: 351-364.

Ong, A. (2006) Neoliberalism as Exception, Chapel Hill: Duke University Press.

Posecznick, A. (2013) 'Constructing legitimacy in a non-selective, American college: unpacking symbolic capital through ethnographic moments', Ethnography and Education 8, no. 1: 1-15.

Rackett, S. (2011) 'Survivor's guilt', Chronicle of Higher Education, 15 March.

Schrecker, E. (2010) The Lost Soul of Higher Education: Corporatization, the Assault on Academic Freedom, and the End of the American University, New York: The New Press.

Scott, J. (1979) The Moral Economy of the Peasant: Rebellion and Subsistence in Southeast Asia, New Haven, CT: Yale University Press.

Scott, J. (1985) Weapons of the Weak: Everyday Forms of Peasant Resistance, New Haven, CT: Yale University Press.

Scott, J. (1990) Domination and the Arts of Resistance: Hidden Transcripts, New Haven, CT: Yale University Press.

Shullenberger, G. (2013) 'An adjunct’s healthcare education', Chronicle of Higher Education, 13 September.

Sivaramakrishnan, K. (2005) 'Some intellectual genealogies for the concept of everyday resistance', American Anthropologist 107, no. 3: 346-355.

Tuchman, G. (2011) Wannabe U.: Inside the Corporate University, Chicago: University of Chicago Press.

Waquant, L. (2008) Urban Outcasts: A Comparative Sociology of Advanced Marginality. Cambridge: Policy Press.

Waquant, L. (2009) Punishing the Poor: The Neoliberal Government of Social Insecurity. Durham and London: Duke University Press.

Waquant, L. (2010) 'Crafting the neoliberal state: workfare, prisonfare and social insecurity', Sociological Forum 25, no. 2: 197-220.

Washburn, J. (2006) University, Inc.: The Corporate Corruption of Higher Education, New York: Basic Books.

Wilson, R. (2013) 'The new faculty minority. Tenured professors fight to retain control as their numbers shrink', Chronicle of Higher Education, 18 March. 